\title{
Review Article \\ Chemical Recycling of PET Wastes with Different Catalysts
}

\author{
Mohammad Khoonkari, ${ }^{1}$ Amir Hossein Haghighi, ${ }^{1}$ Yahya Sefidbakht, ${ }^{2}$ \\ Khadijeh Shekoohi, ${ }^{3}$ and Abolfazl Ghaderian ${ }^{4}$ \\ ${ }^{1}$ Department of Polymer Engineering, Shiraz Branch, Islamic Azad University, Shiraz 71987 74731, Iran \\ ${ }^{2}$ Department of Nanobiotechnology, Protein Research Center, Shahid Beheshti University, G. C. Velenjak, Tehran 19839 4716, Iran \\ ${ }^{3}$ Department of Chemistry, Darab Branch, Islamic Azad University, Darab, Iran \\ ${ }^{4}$ Young Researchers and Elite Club, Shiraz Branch, Islamic Azad University, Shiraz 71987 74731, Iran
}

Correspondence should be addressed to Amir Hossein Haghighi; haghighi.ah@gmail.com

Received 18 June 2015; Revised 15 September 2015; Accepted 16 September 2015

Academic Editor: Yulin Deng

Copyright (C) 2015 Mohammad Khoonkari et al. This is an open access article distributed under the Creative Commons Attribution License, which permits unrestricted use, distribution, and reproduction in any medium, provided the original work is properly cited.

Chemical recycling of polyethylene terephthalate, known as PET, has been the subject of increased interest as a valuable feedstock for different chemical processes. In this work, glycolysis of PET waste granules was carried out using excess ethylene glycol in the presence of different simple chemicals acting as catalysts, which are, namely, categorized in ionic liquids, metal salts, hydrotalcites, and enzymes. From every category, some materials as a sample were used, and the one which is going to bring the best result is noted. The effect of some parameters such as temperature, pressure, amount of sample, material ratio, and stirring rate was investigated. As a result we compared the best of each category with the others and final result is shown.

\section{Introduction}

Polyester is one of the engineering plastics which are frequently used. Polyethylene terephthalate, more commonly known as PET, is one of these polyesters, which is used for tape recorders and videos and is largely used in packaging industry in different forms; also the great usage of PET is in yarn industry. PET, as polyesters family, is a thermoplastic polymer with long branches of those which their wastes can be useable and bring economic benefits by using appropriate recycling methods [1].

Plastic bottles, which are produced from these materials, have been expanded widely. Interestingly, due to the high resistance of these bottles against breakage, temperature, and diffusion of gases, having low weight and having cheaper price in comparison with other packaging materials, such as glass and metals, bring a remarkable state for them in recycling industry [2]. Since 1999, due to increasing trend of using plastic bottle and packages as a worldwide phenomenon that naturally leads to the entry of used PET bottles into the waste stream, recycling has become an important topic. These bottles have high volume compared with their weight ratio which causes occupying lots of space during transport and burial account. On the other hand, analysis of them takes too much time in nature (about 300 years) which occurs by natural agent. Thus, this phenomenon, the problem of recycling these bottles, is going to be in a great deal of attention, especially in recent years [3].

The increasing trend of PET recycling and material utilization was shown in Figure 1 [4]. Clearly, the importance of PET recycling is going to be more and more, especially in recent years, due to mentioned trend.

Based on Figure 2, which shows the extraction resource of PET, the huge extraction resource of PET is from cans that have a great percentage in trash [4]. Trash cans (used in PET recycling) rate increased between 1996 and 1998 and after that it has become more stable, whereas it kept increasing trend smoothly [5].

1.1. Recycling Mechanism and Method. Nowadays many countries have realized the importance of this issue and started to recycle PET bottles and turn them into recycled polyesters in both mechanical and chemical methods according to their needs. Through mechanical recycling, waste PET 


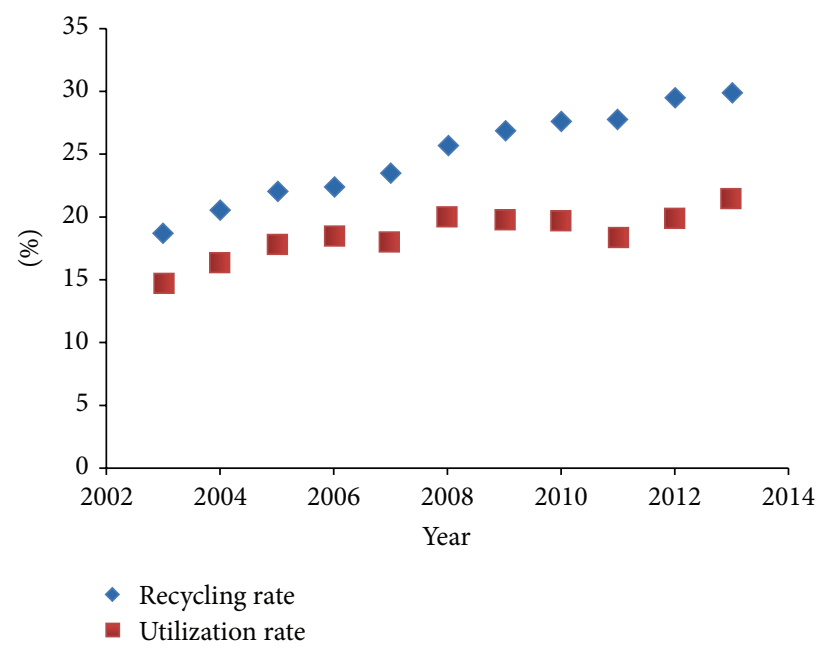

FIgURE 1: PET recycling and PET material utilization ratio [4].

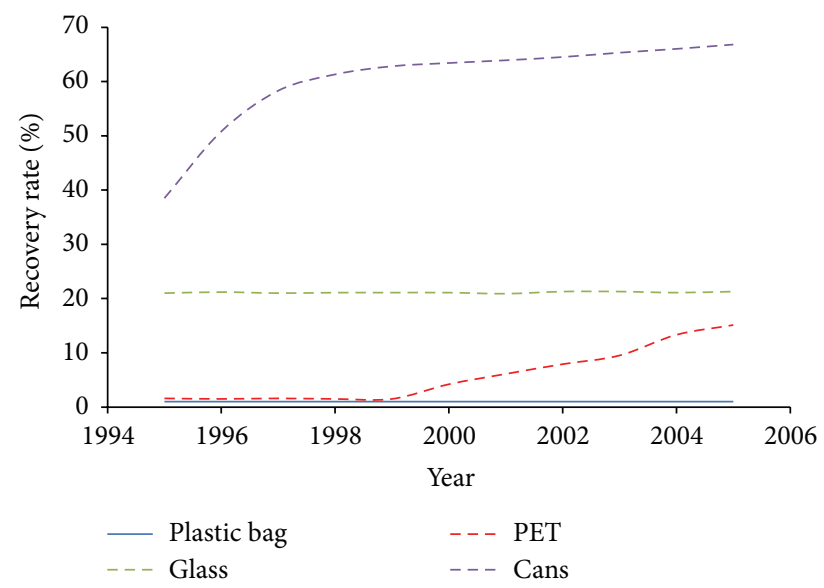

FIGURE 2: Recycling recovery rate of PET sources (trend of recent year) [4].

bottles can be found in films, sheets, strapping packaging, and fiber used for sacking and their usage for insulation and for floor covering has also been studied [6]. By chemical recycling in adequate methods it can be reachable to recover raw material of PET or produce new recycling material from them, which can be reused again. Chemical recycling of PET can be done by acids, methanol, and glycols, with each having its own advantages [3].

Only chemical recycling conforms to the principles of sustainable development because it leads to the formation of the raw materials from which PET is originally made. Chemical recycling utilizes processes such as hydrolysis, methanolysis, glycolysis, ammonolysis, and aminolysis. In a large collection of researches for the chemical recycling of PET, the primary objective is to increase the monomer yield while reducing the reaction time and/or carrying out the reaction under mild conditions. Continuous efforts of researchers have brought about great improvements in the chemical recycling processes [2].

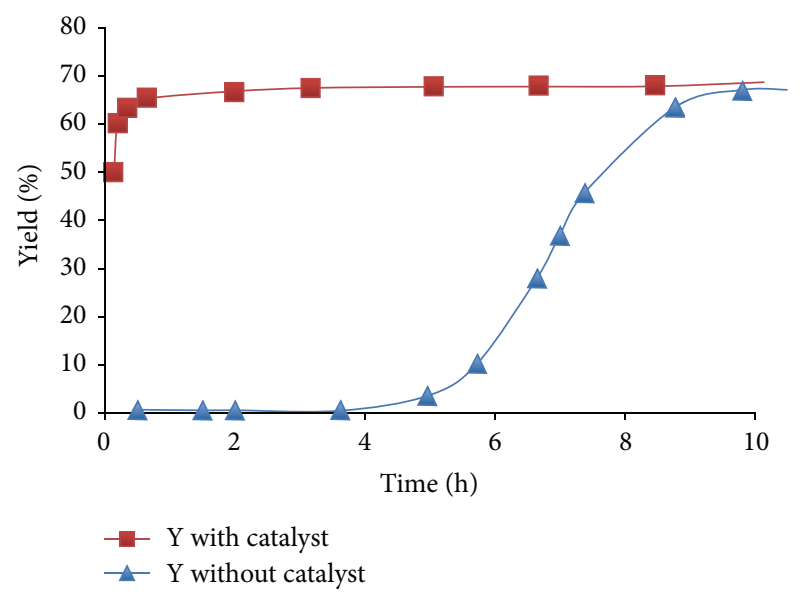

FIGURE 3: The effect of catalyst in yield reaction of PET glycolysis [8].

Glycolysis is one of the various methods that are used in PET recycling, which attracted considerable attention recently. Based on the literature and due to the reasons which are given below $[2,7]$, glycolysis is the best method for PET recycling compared with other methods; the process is conducted in a wide range of temperatures from $180^{\circ} \mathrm{C}$ to $240^{\circ} \mathrm{C}$ [2]; glycolysis is faster and brings about depolymerization in lower time, and with an increased amount of glycol a better depolymerization of PET was obtained. This method has the highest efficiency and quality when the catalyst is used/added [7]. There are the various catalysts which can be used in PET glycolysis, with each of them having its own performance under different conditions of temperature and pressure. The approval goals of this study are going to investigate PET recycling through glycolysis methods examined with different catalysts.

Based on Figure 3 [8], the effect of using catalyst in the reaction is touchable. During normal reaction it takes 4 to 5 hours for a total conversion process to start, and achieving appropriate conversion is possible after 9 hours. But with the use of catalysts within a few seconds of starting the conversion, mechanism is going to be reached, and after a few seconds we have the ideal yield reaction. It shows that since starting, the terms of reaction become ideal.

Metal salts, ionic liquids, and hydrotalcites are the common catalysis of those which are used in PET glycolysis that had their own unique properties and performance under different reaction environment based on different types of temperature and pressure conditions. Furthermore, recently, researchers have found that enzyme can be used as a new degradation biocatalyst for PET. In the following, in brief, we consider some articles about PET degradation with enzyme and other catalysts.

\section{Ionic Liquids}

It has not been long since ionic liquids were applied as catalyst for PET glycolysis when Wang et al. initiated the study and first reported its use in $2009[2,10]$. The main advantage of 
TABLE 1: Catalytic effect of different ionic liquids on the PET glycolysis [9].

\begin{tabular}{lccc}
\hline Entry & Ionic liquids & Temperature $\left({ }^{\circ} \mathrm{C}\right)$ & Conversion of PET $(\%)$ \\
\hline 1 & - & 180 & 10.1 \\
2 & {$[$ bmim $] \mathrm{H}_{2} \mathrm{PO}_{4}$} & 175 & 6.9 \\
3 & {$[\mathrm{bmim}] \mathrm{HSO}_{4}$} & 170 & 0.5 \\
4 & {$\left[3 \mathrm{a}-\mathrm{C}_{3} \mathrm{P}\left(\mathrm{C}_{4}\right)_{3}\right][\mathrm{GLY}]$} & 180 & 100 \\
5 & {$\left[3 \mathrm{a}-\mathrm{C}_{3} \mathrm{P}\left(\mathrm{C}_{4}\right)_{3}\right][\mathrm{Ala}]$} & 180 & 100 \\
6 & {$[\mathrm{bmim}] \mathrm{Cl}$} & 180 & 44.7 \\
7 & {$[\mathrm{bmim}] \mathrm{Br}$} & 180 & 98.7 \\
\hline
\end{tabular}

Reaction condition: $1 \mathrm{~atm}, 8 \mathrm{~h}$, amount of ionic liquid $1.0 \mathrm{~g}$.

TABLE 2: The amount of catalyst, influence on the glycolysis process [9].

\begin{tabular}{|c|c|c|c|c|c|}
\hline \multirow{2}{*}{ Amount of IL (g) } & \multirow{2}{*}{ Conversion of PET (\%) } & \multirow{2}{*}{ Selectivity of BHET (\%) } & \multicolumn{3}{|c|}{ Composition (wt\%) } \\
\hline & & & BHET & Dimer & Oligomers \\
\hline 0.0 & 10.1 & 1.8 & 1.8 & 25.4 & 72.8 \\
\hline 1.0 & 44.7 & 53.7 & 72.4 & 5.7 & 21.9 \\
\hline 2.0 & 54.1 & 63.0 & 76.6 & 4.9 & 18.5 \\
\hline 3.0 & 66.9 & 59.9 & 75.1 & 4.4 & 20.5 \\
\hline 4.0 & 70.1 & 59.4 & 78.0 & 1.9 & 20.1 \\
\hline
\end{tabular}

Reaction condition: $1 \mathrm{~atm}, 180^{\circ} \mathrm{C}, 8 \mathrm{~h}$.

ionic liquids over conventional catalysts like metal acetates is that the purification of the glycolysis products is simpler [2]. They prepared different ionic liquids and performed glycolysis reactions in the presence of these ionic liquids at atmospheric pressure with different temperature and time. $100 \%$ conversion of PET was achieved after 8 hours at a temperature of $180^{\circ} \mathrm{C}$, with 1-butyl-3-methylimidazolium bromide ([bmim] Br) being the best catalyst in terms of PET conversion ease and cost of preparation. They concluded that the BHET purity from their method was high. They did not, however, quantitatively measure the BHET yield from their experiment. After this, they extended their research by investigating the reusability of the ionic liquid catalysts and kinetics of the PET degradation by ionic liquid alone. They concluded that the catalysts can be used repeatedly and that the degradation reaction is first-order with activation energy equal to $232.79 \mathrm{~kJ} / \mathrm{mol}$ and that it can potentially replace the traditional organic solvents used in PET degradation [2, 9]. Recently, they successfully applied Fe containing magnetic ionic liquid as a catalyst for PET glycolysis. They reported that this catalyst has better catalytic activity than the conventional metal salts or the pure ionic liquid with the amount of catalyst affecting the PET conversion and BHET selectivity $[2,9]$.

\subsection{Influence of the Amount and Type of Different Ionic Liquids} Catalyst on the PET Glycolysis. According to Table 1, Br has the highest effect to yield reaction in $180^{\circ} \mathrm{C}$. Interestingly, in $180^{\circ} \mathrm{C}, \mathrm{Br}$ improves the reaction about 98.7 percent, which is absolutely remarkable. The trend shows that with increasing temperature the effect of ionic liquids is going to be more touchable and effect of $\mathrm{Br}$ is still the best in high temperature [9].

According to Table 2, PET can also be partially depolymerized by ethylene glycol in the absence of catalyst, perhaps due to the solvent effect of ethylene glycol in the glycolysis process. As can be seen, by increasing the amount of $\mathrm{Br}$ as a catalyst from 1 to $4 \mathrm{gr}$, PET conversion percentage is going to be enhanced and has growth from $44.7 \%$ to $70.1 \%$. Also in the presence of catalysts BHET selectivity has sharp increase by using 1 gr of catalysts which is changed from $1.8 \%$ to $53.7 \%$ compared with absence of catalysts. By adding more catalysts, selectivity is going to reach nearly $63 \%$ but with increasing the amount of catalysts to 3 gr or 4 gr selectivity has smoothly fallen. Also investigation of composition in different amount of catalysts shows that, with increasing amount of catalysts, BHET value enhances, but the amounts of oligomer and dimer are decreased in contrast, and this decreasing trend is going to be stable after using 4.0 gr of catalyst, and a remarkable change did not happen by increasing amount of catalyst. Therefore, the presence of the catalyst significantly increases the selectivity of BHET monomer in the glycolysis process and according to Table 2 it can be concluded that, with 2 gr of catalysts, the maximum selectivity is achieved which has its optimum value [9].

2.2. Effect of Time and Temperature. Influence of glycolysis time on the product distribution is given in Figures 4 and 5, indicating that, with increasing glycolysis time, the conversion of PET increases distinctly. If the reaction time is extended to 10 hours, the glycolysis conversion could be close to $100 \%$. It also shows that the selectivity of BHET reaches a maximum value when the reaction time is set at 6 hours [9]. However, the effect of reaction time on the product distribution illustrated in Figure 5 is quite complex; with the enhancement of reaction time, the weight percentage of BHET in the final products first increases and then it is going to be declined, while that of the dimer first decreases and then reaches a constant value [9]. Correspondingly, the weight 


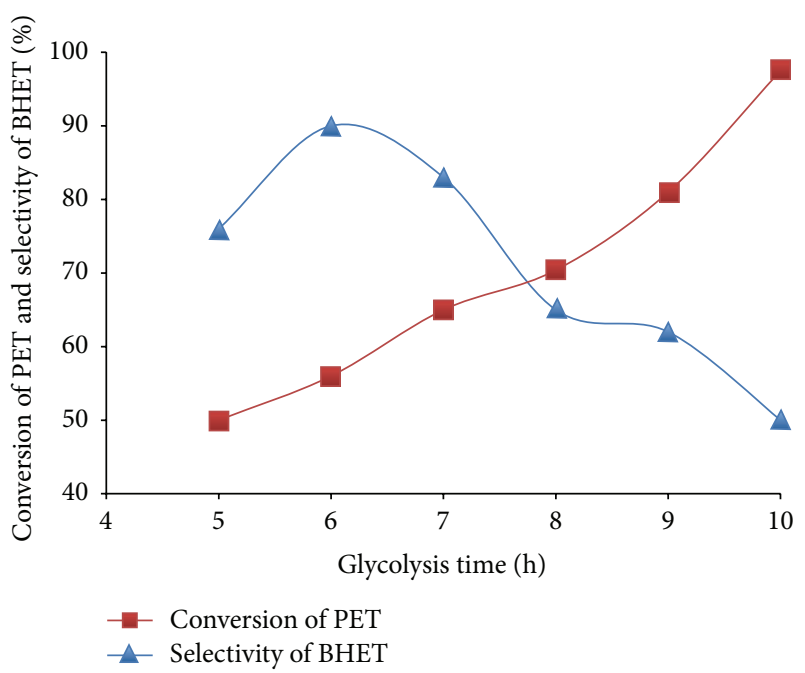

FIGURE 4: Effects of glycolysis time on the conversion of PET and selectivity of BHET ( $1 \mathrm{~atm}, 180^{\circ} \mathrm{C}$, with $4.0 \mathrm{gr}$ of [bmim] Br) [9].

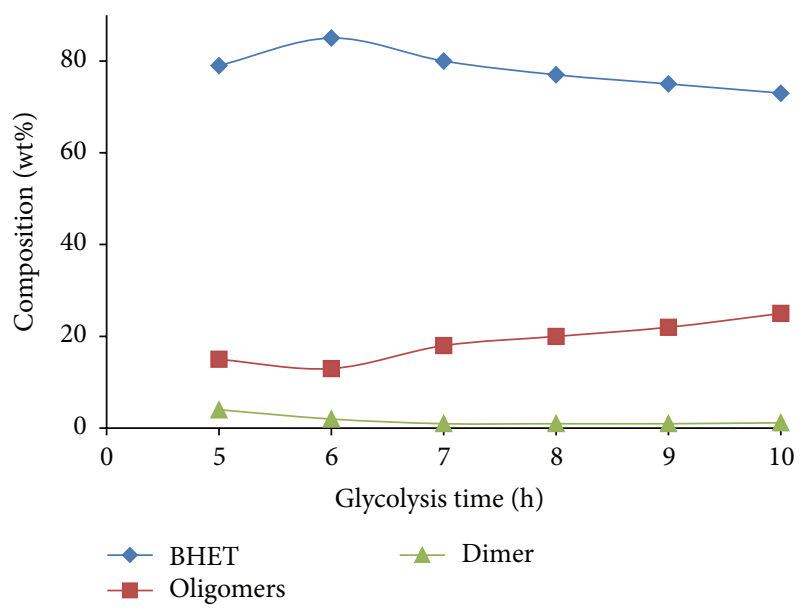

FIGURE 5: Effect of glycolysis time on distribution of the products (1 atm, $180^{\circ} \mathrm{C}$, with $4.0 \mathrm{gr}$ of [bmim] Br) [9].

percentage of the oligomers first decreased and then it is going to be enhanced like the trend which was mentioned before. Thus, it may be concluded that, during the depolymerization process, PET was first depolymerized into oligomers; afterwards, oligomers were converted into dimer and then BHET monomer in the presence of ethylene glycol; with increasing of glycolysis time, BHET would further polymerize into dimer and then oligomers. This would count for the tendency for the selectivity of BHET to first enhance and then decline with an increase of reaction time (Figure 4) [9]. Figure 6 [9] indicates that the proportion of BHET monomer in the products is going to be raised with increase of reaction temperature, and then oligomers diminished with increase in glycolysis temperature. Thus, high temperature is beneficial to the formation of BHET monomer. Therefore, the glycolysis temperature is a critical factor in the glycolysis of PET.

Based on Table 1, mentioned bars [9], and literature review, using ionic liquid in PET glycolysis has led to a great

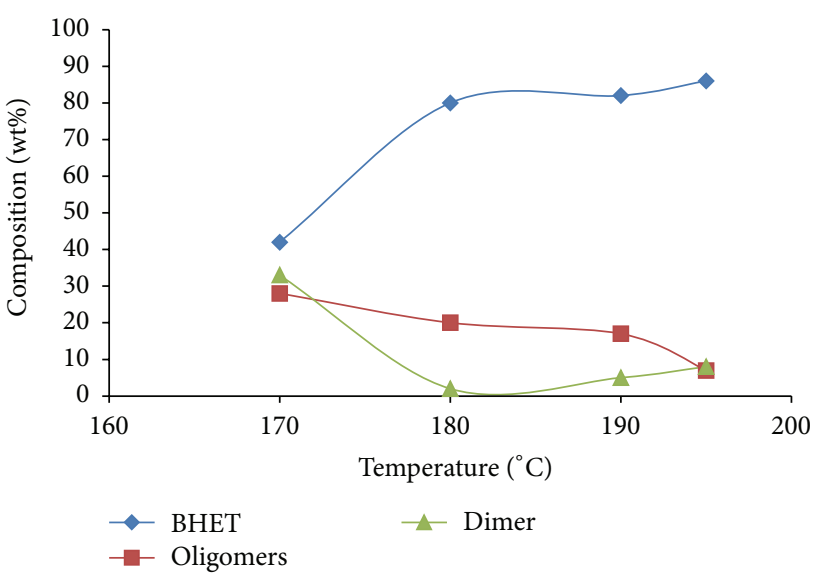

FIGURE 6: Effect of reaction temperature on distribution of the products ( $1 \mathrm{~atm}, 8 \mathrm{hr}$, with $4.0 \mathrm{gr}$ of [bmim] Br) [9].

improvement in yield reaction; in particular, using $\mathrm{Br}$ as ionic liquid for catalyst in high temperature, for example, in $180^{\circ} \mathrm{C}$, increased yield reaction sharply. Using $\mathrm{Br}$ in $180^{\circ} \mathrm{C}$ brings about the ideal yield, but trend shows that, with increasing temperature over $180^{\circ} \mathrm{C}$, achieving a 100 percent of yield reaction is possible.

To sum up, using ionic liquid as a catalyst has a positive effect on yield reaction of PET glycolysis; using $\mathrm{Br}$ in $180^{\circ} \mathrm{C}$ or above brings about great yielding compared with other ionic liquids such as $\mathrm{H}_{2} \mathrm{PO}_{4}, \mathrm{HSO}_{4}$, and $\mathrm{Cl}$, although some ionic liquids like those which are mentioned bring about higher PET conversion percentage compared with $\mathrm{Br}$ [9], but, due to temperature condition and reaction time, totally, $\mathrm{Br}$ is better and more suitable.

\section{Metal Salts}

Metal salts are one of the catalysts which are used for PET glycolysis, eco-friendly active salts as catalysts for the reaction. Hence, an exploratory study of four metal salts (sodium carbonate, sodium bicarbonate, sodium sulphate, and potassium sulphate) was conducted and results were compared with those obtained with the most active catalyst reported in the literature, zinc acetate. The chemical structure of the glycolysis products was analyzed as well. Finally some preliminary results on the glycolysis of different type of PET wastes which have several colors such as green, amber, blue, white, and silver with catalyst are shown in Table 3 [8].

These two mentioned figures (Figures 7 and 8) [8] show the effect of both temperature and EG: PET molar ratio on the reaction. A quick overall view shows that with increasing temperature the yielding is going to be increased; for example, with increasing temperature from $165^{\circ} \mathrm{C}$ to $180^{\circ} \mathrm{C}$, yield reaction is going to be raised, and it seems that $180^{\circ} \mathrm{C}$ is the best temperature which brings about the highest yield process, and, after $180^{\circ} \mathrm{C}$, the trend is stable based on Figure 8 , and with increasing temperature after $180^{\circ} \mathrm{C}$ a big change did not occur. Figure 7 shows show the effect of EG : PET molar ratio on reaction. Investigation shows that, with increasing molar ratio, the yield reaction is going to be improved but it 
TABLE 3: Formulation and amount of materials used in glycolysis [8].

\begin{tabular}{|c|c|c|c|c|c|}
\hline Run & Type of PET waste & Temperature ${ }^{\circ} \mathrm{C}$ & $\begin{array}{c}\text { Amount of EG, } g \\
\text { (EG : PET molar ratio) }\end{array}$ & Catalyst salt & $\begin{array}{c}\text { Amount of catalyst, } g \\
\text { (PET : catalyst molar ratio) }\end{array}$ \\
\hline 1 & Clear & 196 & $73.5(7.6: 1)$ & $\mathrm{Zn}(\mathrm{Ac})_{2}$ & $0.35(98: 1)$ \\
\hline 2 & Clear & 180 & $73.5(7.6: 1)$ & $\mathrm{Zn}(\mathrm{Ac})_{2}$ & $0.35(98: 1)$ \\
\hline 3 & Clear & 165 & $73.5(7.6: 1)$ & $\mathrm{Zn}(\mathrm{Ac})_{2}$ & $0.35(98: 1)$ \\
\hline 4 & Clear & 196 & $73.5(7.6: 1)$ & $\mathrm{Zn}(\mathrm{Ac})_{2}$ & $0.09(381: 1)$ \\
\hline 5 & Clear & 196 & $73.5(7.6: 1)$ & $\mathrm{Zn}(\mathrm{Ac})_{2}$ & $0.14(245: 1)$ \\
\hline 6 & Clear & 196 & $73.5(7.6: 1)$ & $\mathrm{Zn}(\mathrm{Ac})_{2}$ & $0.035(980: 1)$ \\
\hline 7 & Clear & 196 & $73.5(7.6: 1)$ & $\mathrm{Zn}(\mathrm{Ac})_{2}$ & $0.0035(9800: 1)$ \\
\hline 8 & Clear & 196 & $73.5(7.6: 1)$ & $\mathrm{Na}_{2} \mathrm{CO}_{3}$ & $0.045(381: 1)$ \\
\hline 9 & Clear & 196 & $73.5(7.6: 1)$ & $\mathrm{NaHCO}_{3}$ & $0.034(381: 1)$ \\
\hline 10 & Clear & 196 & $73.5(7.6: 1)$ & $\mathrm{Na}_{2} \mathrm{SO}_{4}$ & $0.058(381: 1)$ \\
\hline 11 & Clear & 196 & $73.5(7.6: 1)$ & $\mathrm{K}_{2} \mathrm{SO}_{4}$ & $0.071(381: 1)$ \\
\hline 12 & Clear & 196 & $73.5(7.6: 1)$ & $\mathrm{Na}_{2} \mathrm{CO}_{3}$ & $0.168(98: 1)$ \\
\hline 13 & Clear & 196 & $73.5(7.6: 1)$ & $\mathrm{Na}_{2} \mathrm{CO}_{3}$ & $0.068(245: 1)$ \\
\hline 14 & Clear & 196 & $73.5(7.6: 1)$ & $\mathrm{Na}_{2} \mathrm{CO}_{3}$ & $0.033(503: 1)$ \\
\hline 15 & Clear & 196 & $73.5(7.6: 1)$ & $\mathrm{NaHCO}_{3}$ & $0.069(190: 1)$ \\
\hline 16 & Green & 196 & $73.5(7.6: 1)$ & $\mathrm{Zn}(\mathrm{Ac})_{2}$ & $0.35(98: 1)$ \\
\hline 17 & Amber & 196 & $73.5(7.6: 1)$ & $\mathrm{Zn}(\mathrm{Ac})_{2}$ & $0.35(98: 1)$ \\
\hline 18 & Silver & 196 & $73.5(7.6: 1)$ & $\mathrm{Zn}(\mathrm{Ac})_{2}$ & $0.35(98: 1)$ \\
\hline 19 & Blue & 196 & $73.5(7.6: 1)$ & $\mathrm{Zn}(\mathrm{Ac})_{2}$ & $0.35(98: 1)$ \\
\hline 20 & White & 196 & $73.5(7.6: 1)$ & $\mathrm{Zn}(\mathrm{Ac})_{2}$ & $0.35(98: 1)$ \\
\hline 21 & Multilayered & 196 & $73.5(7.6: 1)$ & $\mathrm{Zn}(\mathrm{Ac})_{2}$ & $0.35(98: 1)$ \\
\hline
\end{tabular}

30 gr of PET ( $0.25 \mathrm{~mm}$ particle size) waste was used in all experiments.

is limited like temperature effect. With increasing this ratio from 4 to 6 , improvement is touchable, but after 6 (as molar ratio), the trend was stable and a remarkable change did not occur. Literature study shows that, with increasing temperature, EG: PET ratio, and catalysis percentage, a remarkable change in yield reaction occurred and the process is going to be improved.

Based on literature review, the best catalyst is zinc acetate which has the best improvement effect on the reaction compared with others (Figure 9) [8]. Zinc acetate as a catalyst had the best efficiency in the temperature range from $180^{\circ} \mathrm{C}$ to $195^{\circ} \mathrm{C}$ [11]. It shows that if yield reaction was done by zinc acetate, which is the best of metal salts, with fixed reaction temperature between $180^{\circ} \mathrm{C}$ and $190^{\circ} \mathrm{C}$, the efficiency is being ideal.

In another work by López-Fonseca and his colleagues [12], with regard to the problems of metal acetate catalyst, including toxicity, nonbiodegradability and nonselectivity of the final product (monomer, dimer, and trimmer), and the difficulty of separating with conventional approaches, their study on the effects of four biocompatible catalysts included sodium carbonate, sodium bicarbonate, sodium sulfate, and potassium sulfate in recycled PET by glycolysis method and compared them with the effect of zinc acetate catalyst as a current one.

Figure 9 shows that zinc acetate brings about $65 \%$ of yielding, which is the best one compared with others [8].
3.1. Investigation of Reaction Condition in the Presence of Metal Salt as a Catalyst. The effects of temperature, time, molar ratio of glycolysis agent with PET, the type of catalyst, and amount of that due to the recycling process have been investigated in López-Fonseca et al.s work [12]; also the effects of PET type such as transparent or colored and multilayered nature of it in the recycling process have been investigated. To investigate temperature effect, they set the process temperature in a range from $165^{\circ} \mathrm{C}$ to $195^{\circ} \mathrm{C}$ until 8 hours, in the three different molar ratios of ethylene glycol/PET $(3: 8,5: 7$, and $7: 6$ ), with different molar ratio of the PET/catalyst, respectively [8].

Based on the primary PET molar amount and obtained BHET molar ratio, they calculate the reaction yields (Scheme 1) [8].

In this study [12], they have done different formulations to optimize the reaction conditions, as can be seen in Table 3. To evaluate the effect of reaction time, the process was examined in two different modes [13], in the absence of a catalyst and in the presence of one. They found that, in the absence of catalyst, the reaction rate is very low and takes a lot of time, more than 8 hours, to achieve a similar outcome to that in the presence of catalyst needed. But in the presence of a catalyst, in less than an hour $(0.33 \mathrm{hr})$, about $70 \%$ efficiency attained over time, and after that significant changes occurred in the reaction efficiency. It should be noted that if the reaction time is going to be longer, due to a water production and increasing 


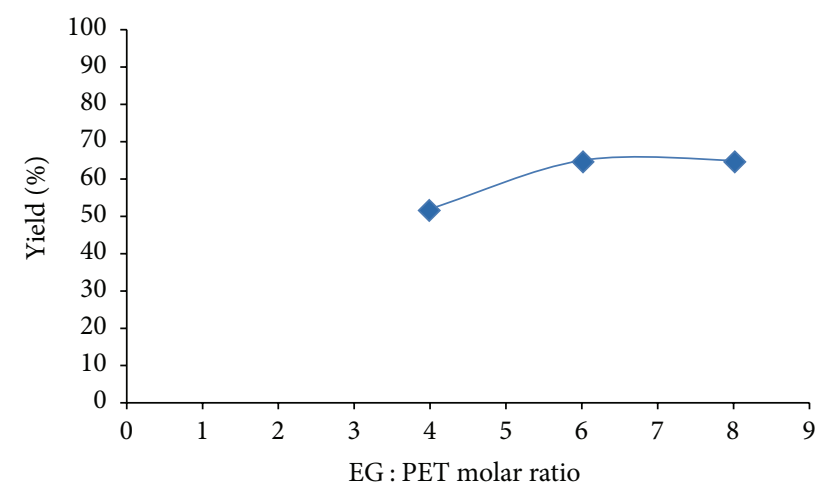

FIgURE 7: The effect of EG : PET molar ratio on BHET yield $\left(196^{\circ} \mathrm{C}\right.$, PET : catalyst molar ratio $380: 1,1 \mathrm{hr}$ ) [8].

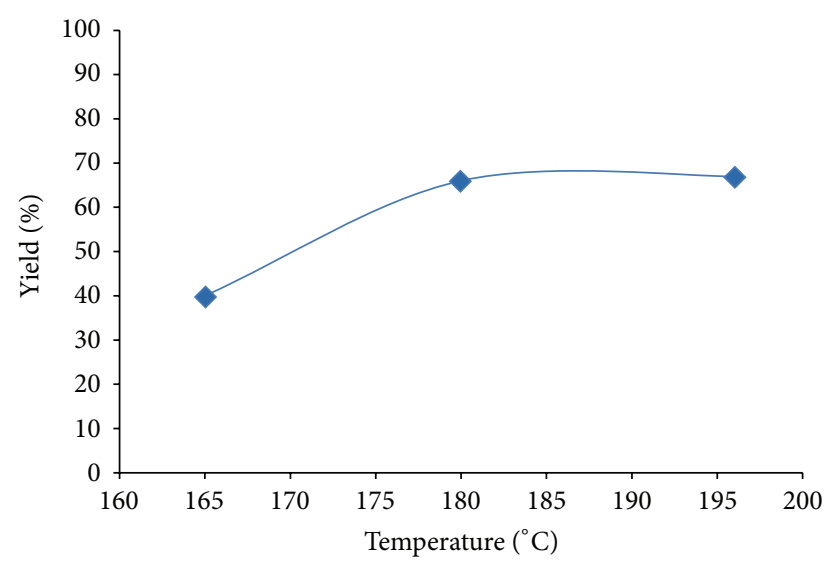

FIGURE 8: The effect of reaction temperature on BHET yield (EG : PET molar ratio 7.6:1, PET: $\mathrm{Zn}(\mathrm{Ac})_{2}$ molar ratio $100: 1$ ) [8].

in BHET density, reversible reactions are carried out and that leads to a reduction of reaction efficiency. Thus, prolonging the reaction time is not desirable. In addition, López-Fonseca et al. stated that when enough BHET and oligomers were produced, thereby increasing the response time, this leads to occurring reaction in liquid phase since the equilibrium has been seen. Also López-Fonseca et al. investigated the effect of temperature by subtracting temperature from $196^{\circ} \mathrm{C}$ as boiling point of ethylene glycol to $185^{\circ} \mathrm{C}$, and that has lead to declining the yield of BHET from 70 molar percent to 67 molar percent; moreover, in another temperature like $165^{\circ} \mathrm{C}$, the decreasing trend in BHET yield is continued and the molar percent has fallen to 34 [12].

Based on Table 3 [8], it can be seen that different amount of PET waste with different catalysts in the same temperature brings about some results which are investigated to choose the best one. At last, it is investigated that zinc acetate as the catalyst is the best one and is more better in increasing yield reaction and achieved a higher percentage of efficiency.

\section{Hydrotalcite}

The use of nanomaterials in the polymer industry is the newest way, which has its own benefits in reaction process and

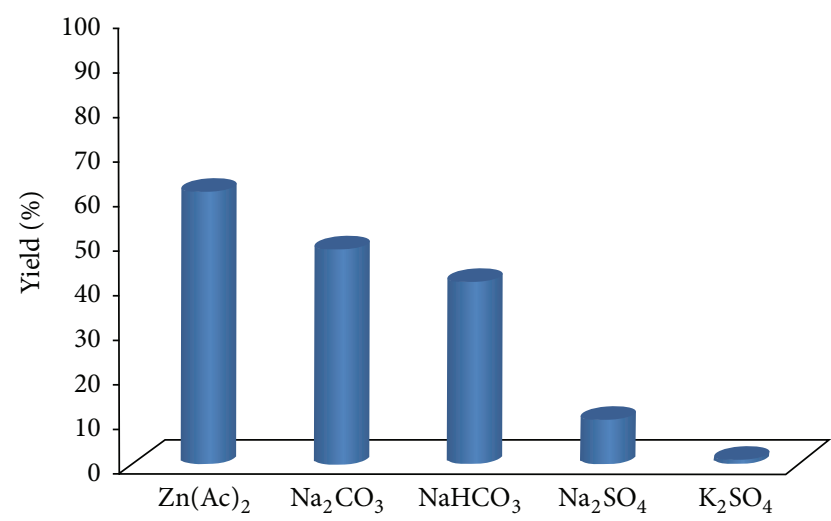

FIGURE 9: The effect of zinc acetate compared to others (BHET) yields in the glycolysis of clear PET catalyzed by several metal salts $\left(196^{\circ} \mathrm{C}, \mathrm{EG}\right.$ : PET molar ratio 7.6 :1, PET : catalyst molar ratio $380: 1$ ) [8].

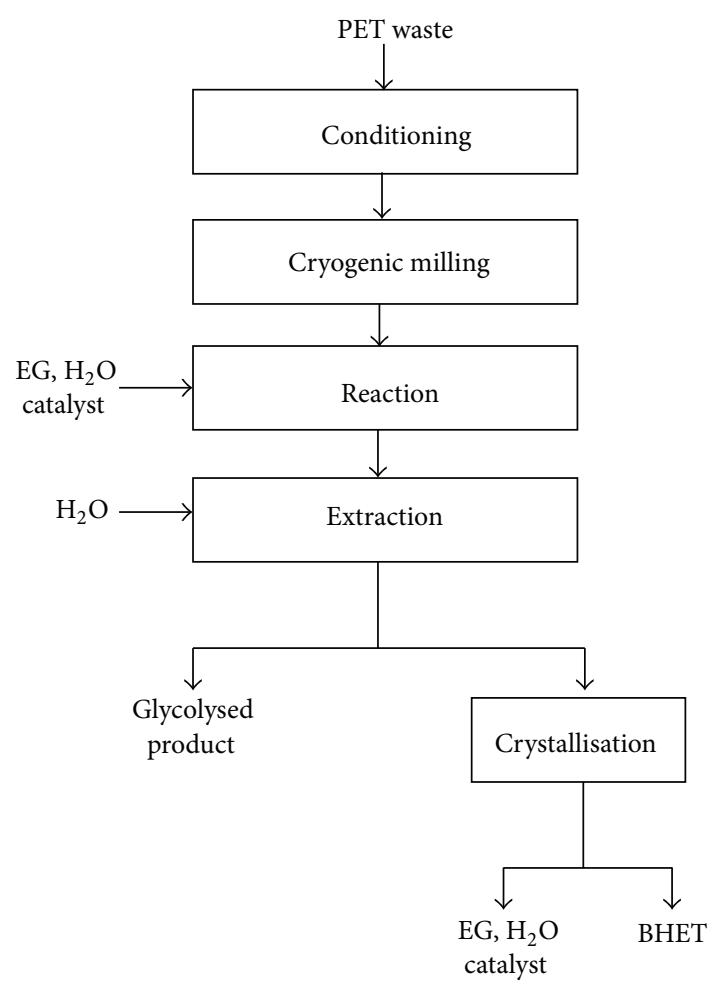

SCHEME 1: Schematic diagram of the reaction and analytical procedure for the glycolysis of PET [8].

final products. One of these materials is nanoclays. Hydrotalcites are one of these nanoclays which have a usage in PET glycolysis and bring about some special effects on glycolysis process.

Hydrotalcite catalyzed synthesis of polyethylene terephthalate was studied to clarify the effect of hydrotalcite properties on its catalytic activity [15]. Hydrotalcite was modified by various treatments to tune its activity as a polycondensation catalyst [14]. Hydrotalcite activity was found to decrease upon calcination. However, rehydration of the calcinated hydrotalcite resulted in higher catalytic activity than that of 

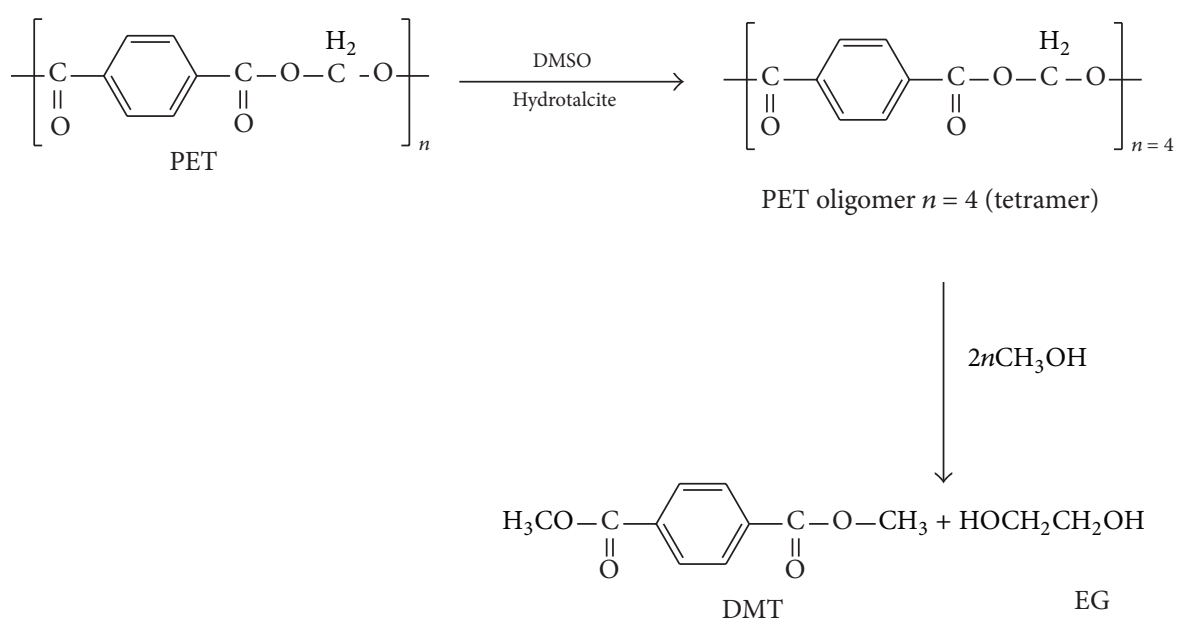

SCHEME 2: Mechanism of PET degradation by using hydrotalcites [14].

the untreated catalyst. Hydrotalcite activity is dependent on the ratio of magnesium to aluminum cations in its composition, and highest activity occurs at a molar ratio of two. Replacement of the carbonate anions of hydrotalcite by more nucleophilic ones like hydroxide and alkoxide groups resulted in a faster polycondensation reaction. Hydrotalcite has two assembly orders: primary, lamination of sheets into plates, and secondary, agglomeration of plates into particles [14, 15]. Hydrotalcite with larger sheet size showed lower activity. On the other hand, milling of hydrotalcite particles did not affect their activity as they probably enters the reaction on a plate level, which is not affected by milling. Polycondensation resulted in expansion of the hydrotalcite sheets under the effect of formed polymer. Reuse of hydrotalcite after polycondensation followed by polycondensation resulted in a large activity enhancement [16].

Recently, the researchers at the Dow Chemical Company have patented HT-like compounds as safer, cheaper, and more efficient catalysts for PET production $[15,16]$. It is a hazardless material and can be applied in contact with food without any restrictions. In order to optimize the catalytic activity of HT as a polycondensation catalyst, the effect of the ratio of aluminum to magnesium in its compositions, hydroxide groups content, the type of counterbalancing anions, the size of layers, and interlayer distance on HT catalytic activity were studied [16].

4.1. Degradation Reaction. The degradation of PET bottle was achieved in 10 minutes using hydrotalcite $\left(\mathrm{Al}: \mathrm{Mg}: \mathrm{CO}_{3}\right)$ as catalyst in solvent DMSO. The oligomer on treatment with sodium hydroxide in methanol at room temperature resulted in the precipitation of MT and EG in methanol, according to the following chemical reaction (Scheme 2) [14].

The effect of degradation temperature on the degradation of PET with hydrotalcite catalyst in temperature range of $120-$ $190^{\circ} \mathrm{C}$ at different time periods is shown in Figure 10 [14]. The results show that the catalytic activity increased by increasing reaction temperature, and the rate of degradation is also enhanced as the reaction temperature rises and maximum

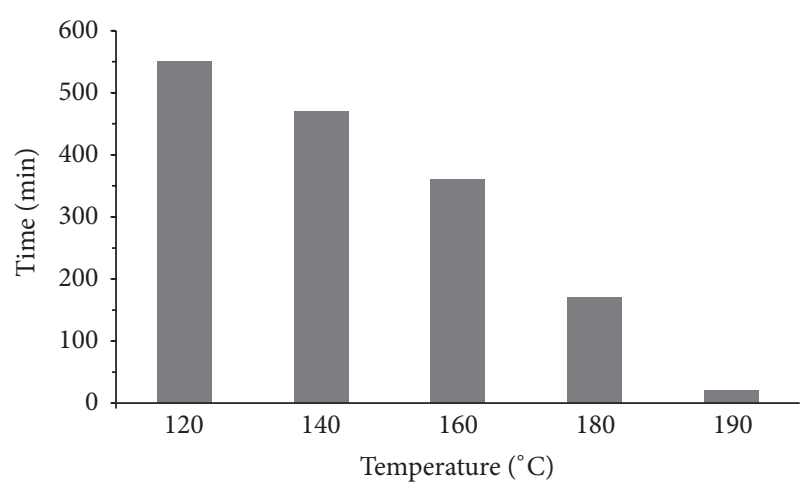

FIGURE 10: Effect of temperature on the time of reaction [14].

conversation of $98 \%$ was observed at $190^{\circ} \mathrm{C}$ in 10 minutes. The remaining $2 \%$ oligomer stays dissolved in DMSO which got separated on recovery of DMSO by distillation [14]. Hence, this temperature was selected for further studies. It was observed that degradation was slow at $180^{\circ} \mathrm{C}$ and degradation was completed in 180 minutes and further decreases in temperature from $180^{\circ} \mathrm{C}$ to $160^{\circ} \mathrm{C}$ and from $160^{\circ} \mathrm{C}$ to $120^{\circ} \mathrm{C}$ increased degradation time from 180 to 360 minutes and from 360 to 540 minutes, respectively (Figure 11). Different concentrations of catalyst were used, but PET was completely depolymerized at $0.5 \mathrm{gr}$ hydrotalcite in 10 minutes. At lower concentration of catalyst ( $0.05 \mathrm{gr})$, PET was not completely depolymerized and conversion time was too high [14].

It can be concluded that hydrotalcite in presence of DMSO as solvent can degrade PET within 10 minutes to afford oligomer (tetramer). The oligomer (tetramer) using sodium hydroxide can be transesterified to DMT and EG at room temperature. The hydrotalcite can be recycled again. The oligomer (tetramer) has been found to be pure. The EG recovered is pure as confirmed by GC-MS. Thus, hydrotalcite can be used as recyclable catalyst for the degradation of PET to DMT and EG [14]. 


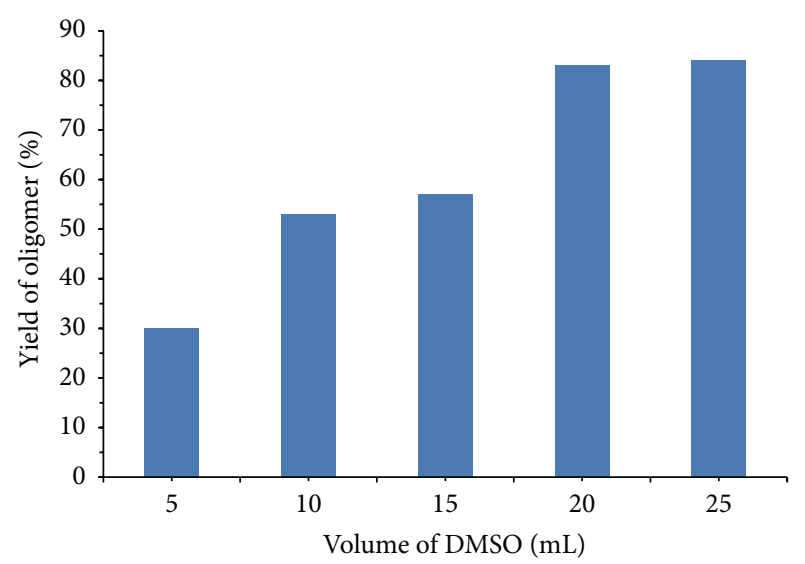

FIGURE 11: Effect of volume of solvent (DMSO) on the yield of oligomers (tetramer) [14].

\section{Enzymes}

Biotechnological environmental friendly methods based on enzyme catalysis have been provided with many advantages compared with classical chemical processes and nowadays are under promising investigations [17]. Hopefully, enzyme technology could be applicable in large scale such as, in term, improving green industries especially in dealing with production (such as detergents) or recycling and detoxifying of daily products.

Advantages of enzymatic methods include the fact that their action under mild conditions with low energy input without the need for expensive machinery might be helpful in PET degradation [18]. Enzymes which are capable of biodegrading PET have been described from variety of fungal and bacterial sources [19]. PET degradation activity has been reported for members of the cutinase [20], lipase [21], and esterase $[22,23]$. The extent of degradation of PET using cutinase from Fusarium solani pisi and lipase from Candida antarctica was detected by measuring the amount of soluble degradation products using reversed phase HPLC [24].

PET is a nonnatural substrate for enzymatic reactions and therefore classically is considered as recalcitrant to biodegradation, which results in slow enzymatic rate toward this polymer [25]. Hence, protein engineering approach was used to increase the affinity of cutinase to PET and the ability to hydrolyze it [26]. The other limiting factor is due to the fact that biodegradability of the PET and generally other polymers strongly increased at reaction temperatures close to the transition temperature $\left(T_{g}\right.$, which is about $71^{\circ} \mathrm{C}$ for amorphous PET). Therefore, the site directed mutagenesis and protein engineering studies were performed to increase thermal stability of cutinase [20].

According to studies on enzymatic degradation of PET, this limitation has been shown to be stemmed from the increase in polymer chain flexibility upon heating in amorphous regions and consequently becoming more accessible to the enzyme catalytic site [27]. Hence, the flexibility, spatial configuration of polymer chains, and presence of solvent media would be major factors. But the efficiency of degradation reaction is low and, based on Then et al., is near 15\% [20].

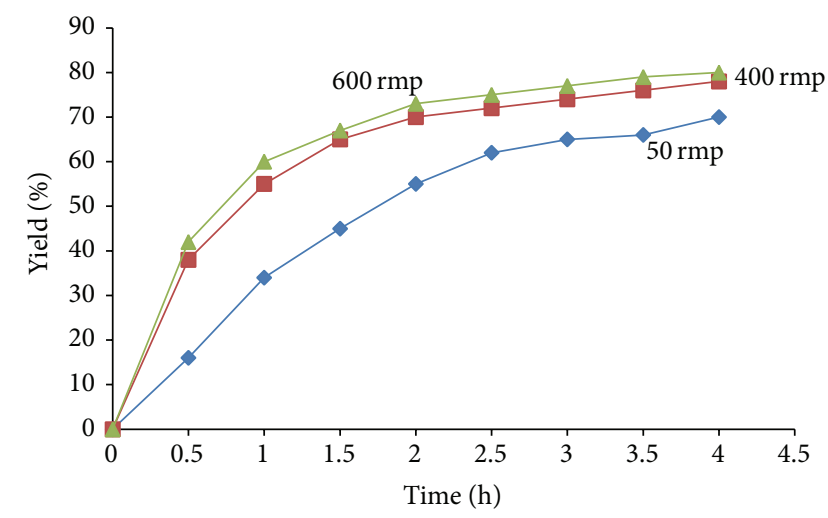

FIGURE 12: The effect of stirring speed on the efficiency in reaction conditions, $196^{\circ} \mathrm{C}, \mathrm{PET}:$ catalyst $=100: 1[12]$.

Moreover, for solving this problem other researchers such as Ribitsch et al. have shown that the rate of this degradation can be enhanced by the addition of hydrophobins (recombinant fusion enzyme). They have declared additional hydrophobins (HFB4 and HFB7) which could have altered the physicochemical properties of enzyme surfaces which in term lead to 15 -fold increase in PET degradation $[28,29]$.

Overall, converting PET materials to TPA and ethylene glycol under mild conditions could be achieved through further studies and needed more activities until the degradation efficiency increased [19].

\section{Special Effect of Some Parameters Which Have Influenced the Reaction Process}

Generally, there are various factors that can be effective in glycolysis reaction and its final product. Some of these factors were studied as follows.

6.1. Effect of Stirring Speed. According to Figure 12, the effect of stirring speed, under identical conditions, is observed. Based on the experiments, it can be concluded that the reaction efficiency is going to be increased with increasing the stirring speed but it has been limited, meaning that the efficiency is going to be increased since some set point, and speeding up the stirring will not work after that and the change will be made in the period. The optimal rate of stirring was estimated at 400 to $600 \mathrm{rpm}$. Expressed $50 \mathrm{rpm}$ for speed led to very low reaction efficiency and needs a lot of time [12].

6.2. Effect of Particle Size. It was also observed that decreasing particle size led to a better PET decomposition due to the increased surface area (Figure 13); thus the particle which had $0.25-0.35 \mathrm{~mm}$ dimension is more suitable and brings about a higher degradation rate $[12,30]$.

6.3. Solvent and Its Ratio. The type and amount of used glycol in this method have a significant impact on the properties of the final products. The most commonly used glycols in this method are ethylene glycol (EG), neopentyl glycol (NPG), propylene glycol (PG), and diethylene glycol (DEG). 


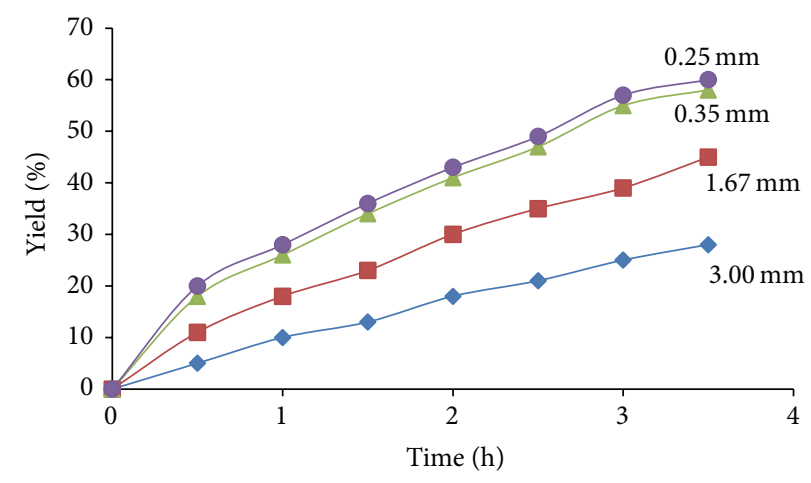

FIGURE 13: The effect of particle dimension on the reaction efficiency [12].
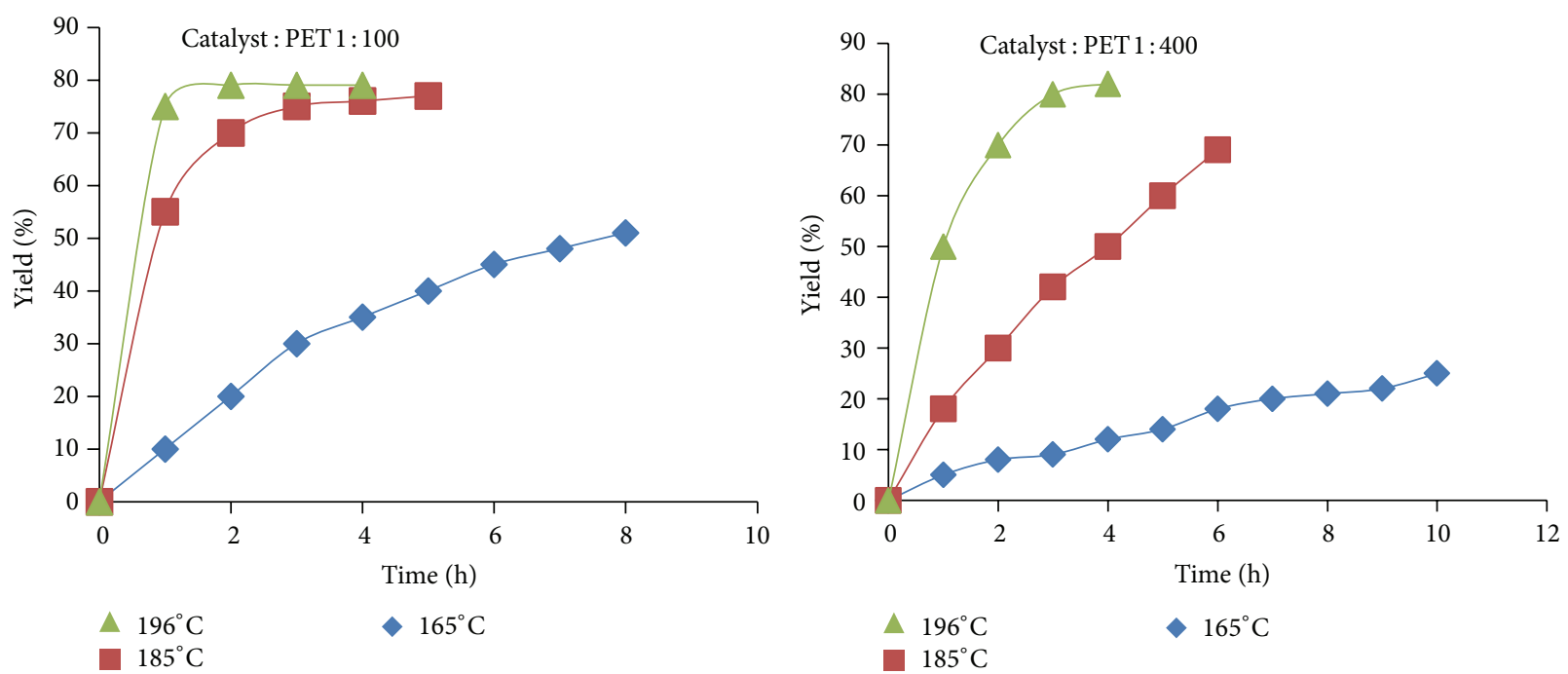

FIGURE 14: The effect of temperature, time, and concentration of catalyst on the yield reaction in the presence of sodium carbonate [12].

Meanwhile the mixture of some glycols, according to the desired properties, is used. But among the types of glycols mentioned, EG, PG, and DEG are the most common; however, EG is more suitable and brings about remarkable result in PET depolymerization $[9,31]$.

It should be noted that the most important factor affective in PET glycolysis is glycol/PET ratio. Due to increasing this ratio, the rate of decomposition is going to be increased and leads to producing lower weight oligomers. However, this ratio (glycol/PET) is an optimum value, and the balance between EG, oligomers, BHET established, and degradation rate reaches a constant value. The high proportion of glycol/PET ratio [9], which is suitable for achieving lower molecular weight of oligomers, can cause problems in the mixing process. Therefore, to solve the problem of litter, Xylene can be used [32]. Xylene causes an increase in reaction rate, because PET and DEG are insoluble in Xylene, even at high temperatures [32]. But the products of glycolysis are solved in Xylene [9,33]. Therefore, with transfer of products from the reaction phase (droplets suspended glycol and PET) to carry Xylene, the reaction is going to be out of balance and goes further. On the other hand, it is easier to separate the products of glycolysis by using Xylene, which means that separation occurred at low temperature in excess of glycol phase [9].

6.4. The Reaction Conditions (Temperature, Pressure, and Time). The effect of various parameters such as temperature, pressure, and time was studied in many research activities. As can be seen in Figure 14, based on López-Fonseca et al's study [12], it can be observed that, by increasing the reaction temperature, time, and concentration of catalyst, the efficiency or rate of degradation increases and due to the investigation they stated that the effect of temperature on the reaction efficiency is greater compared with the effect of catalyst concentration. Based on Figure 14 [12], it shows that, by increasing the reaction time, since equilibrium, reaction efficiency is increased and then it is going to be frozen and will not change, which is proportional to temperature and catalyst concentration. Also, due to the increasing efficiency by growth of temperature, it is touchable that the reaction is endothermic $[12,13]$.

Generally, the optimum value for the exact time and temperature is raised and reached a minimum value for this parameter which is less than the amount of reaction that does not proceed or is incomplete [6]. For example, in less time 
than 1 to 5 hours, it has not yet become a full PET or if the reaction temperature is below the boiling point temperature of the glycol, the reaction does not occur. But for other particles, 5 to $127 \mu \mathrm{m}$ [9] is obtained as optimum. Also, it has been suggested that the morphology of the lesions has no effect on the rate.

\section{Conclusion}

It can be concluded that, firstly, using metal salts as a catalyst in PET recycling brings about good yielding reaction and acceptable results, but on the other hand it took more time to start reaction compared with ionic liquids and hydrotalcites; also the amount of using zinc acetate as metal salt catalysis is more than that in the other catalyses such as $\mathrm{Br}$ as ionic liquid catalysts and hydrotalcites. So not only does it take more time to start the reaction but also the reaction environment needs a higher temperature; also the purity of final product is less than that in the other tested catalyses. Hopelessly, zinc acetate retrieval reaction is a bit difficult, so economically using zinc acetate as a catalyst costs too much. Secondly, to investigate using ionic liquids in PET recycling, using $\mathrm{Br}$ as ionic liquid brings about perfect results. Reaction starts much faster compared to those which experiment with zinc acetate. Although the reaction is going to be perfectly done in high temperature, which is near to zinc acetate temperature condition ratio, in some points the yielding reaction percentage reached a hundred, which is certainly remarkable. The purity of final product is better than that using zinc acetate. Also the reaction time is more acceptable, but $\mathrm{Br}$ is a temperature sensitive material, and it is being possible that $\mathrm{Br}$ is going to be destroyed in high temperature, which brings about higher yielding. So recycling $\mathrm{Br}$ is not performed, and that is one of the cons of using Br. Finally the results of using hydrotalcites as a newest catalysis in PET recycling are as follows: the reaction starts faster compared to using metal salts and ionic liquids, although the reaction takes a little bit more time than that in the other experiment catalysts, but the reaction environment needs a lower temperature range. Amazingly, hydrotalcites retrieval reaction is easily done and hydrotalcites are the recyclable catalysis in high percentage, which are in both amount of usage and amount of retrieval due to the fact that recycling is more affordable. Also the purity of final products is in perfect range and acceptable.

\section{Conflict of Interests}

The authors declare that there is no conflict of interests regarding the publication of this paper.

\section{References}

[1] F. Welle, "Twenty years of PET bottle to bottle recycling-an overview," Resources, Conservation and Recycling, vol. 55, no. 11, pp. 865-875, 2011.

[2] L. Bartolome, M. Imran, B. G. Cho, W. A. Al-Masry, and D. H. Kim, "Recent developments in the chemical recycling of PET," in Material Recycling-Trends and Perspectives, D. Achilias, Ed., InTech, 2012.
[3] V. Sinha, M. R. Patel, and J. V. Patel, "PET waste management by chemical recycling: a review," Journal of Polymers and the Environment, vol. 18, no. 1, pp. 8-25, 2010.

[4] PACIA, "National Plastics Recycling Survey," Plastics and Chemicals Industries Association, 2002, http://www.pacia.org .au/.

[5] C. Lorenzetti, P. Manaresi, C. Berti, and G. Barbiroli, "Chemical recovery of useful chemicals from polyester (PET) waste for resource conservation: a survey of state of the art," Journal of Polymers and the Environment, vol. 14, no. 1, pp. 89-101, 2006.

[6] A. Ghaderian, A. H. Haghighi, F. A. Taromi, Z. Abdeen, A. Boroomand, and S. M.-R. Taheri, "Characterization of rigid polyurethane foam prepared from recycling of PET waste," Periodica Polytechnica Chemical Engineering, vol. 59, no. 4, pp. 296305, 2015.

[7] M. Y. Abdelaal, T. R. Sobahi, and M. S. I. Makki, "Chemical transformation of pet waste through glycolysis," Construction and Building Materials, vol. 25, no. 8, pp. 3267-3271, 2011.

[8] R. López-Fonseca, I. Duque-Ingunza, B. de Rivas, S. Arnaiz, and J. I. Gutiérrez-Ortiz, "Chemical recycling of post-consumer PET wastes by glycolysis in the presence of metal salts," Polymer Degradation and Stability, vol. 95, no. 6, pp. 1022-1028, 2010.

[9] H. Wang, Y. Liu, Z. Li, X. Zhang, S. Zhang, and Y. Zhang, "Glycolysis of poly(ethylene terephthalate) catalyzed by ionic liquids," European Polymer Journal, vol. 45, no. 5, pp. 1535-1544, 2009.

[10] H. Wang, Z. Li, Y. Liu, X. Zhang, and S. Zhang, "Degradation of poly(ethylene terephthalate) using ionic liquids," Green Chemistry, vol. 11, no. 10, pp. 1568-1575, 2009.

[11] M. Imran, D. H. Kim, W. A. Al-Masry et al., "Manganese-, cobalt-, and zinc-based mixed-oxide spinels as novel catalysts for the chemical recycling of poly(ethylene terephthalate) via glycolysis," Polymer Degradation and Stability, vol. 98, no. 4, pp. 904-915, 2013.

[12] R. López-Fonseca, I. Duque-Ingunza, B. de Rivas, L. FloresGiraldo, and J. I. Gutiérrez-Ortiz, "Kinetics of catalytic glycolysis of PET wastes with sodium carbonate," Chemical Engineering Journal, vol. 168, no. 1, pp. 312-320, 2011.

[13] F. A. El-Toufaili, Catalytic and mechanistic studies of polyethylene terephthalate synthesis [Ph.D. dissertation], Technical University, Berlin, Germany, 2006.

[14] V. Sharma, P. Parashar, P. Srivastava, S. Kumar, D. D. Agarwal, and N. Richharia, "Recycling of waste PET-bottles using dimethyl sulfoxide and hydrotalcite catalyst," Journal of Applied Polymer Science, vol. 129, no. 3, pp. 1513-1519, 2013.

[15] H. Xue, F. Wang, G. Li, P. Liu, Y. Bai, and K. Wang, "Synthesis method and its influence factors of hydrotalcite-like compounds," Advanced Materials Research, vol. 690-693, pp. 351354, 2013.

[16] P. Parashar, P. K. Bohre, D. D. Agarwal, and N. Richhariya, "Recycling of polystyrene using hydrotalcite as degradation catalyst," International Journal of Modern Engineering \& Management Research, vol. 1, no. 3, pp. 53-56, 2013.

[17] P. A. Schulte, L. T. McKernan, D. S. Heidel et al., "Occupational safety and health, green chemistry, and sustainability: a review of areas of convergence," Environmental Health, vol. 12, article 31, 2013.

[18] G. Fischer-Colbrie, S. Heumann, S. Liebminger, E. Almansa, A. Cavaco-Paulo, and G. M. Guebitz, "New enzymes with potential for PET surface modification," Biocatalysis and Biotransformation, vol. 22, no. 5-6, pp. 341-346, 2004. 
[19] Å. M. Ronkvist, W. Xie, W. Lu, and R. A. Gross, "Cutinasecatalyzed hydrolysis of poly (ethylene terephthalate)," Macromolecules, vol. 42, no. 14, pp. 5128-5138, 2009.

[20] J. Then, R. Wei, T. Oeser et al., " $\mathrm{Ca}^{2+}$ and $\mathrm{Mg}^{2+}$ binding site engineering increases the degradation of polyethylene terephthalate films by polyester hydrolases from Thermobifida fusca," Biotechnology Journal, vol. 10, pp. 592-598, 2015.

[21] A. Eberl, S. Heumann, T. Brückner et al., "Enzymatic surface hydrolysis of poly(ethylene terephthalate) and bis(benzoyloxyethyl) terephthalate by lipase and cutinase in the presence of surface active molecules," Journal of Biotechnology, vol. 143, no. 3, pp. 207-212, 2009.

[22] Y. Tokiwa, B. P. Calabia, C. U. Ugwu, and S. Aiba, "Biodegradability of plastics," International Journal of Molecular Sciences, vol. 10, no. 9, pp. 3722-3742, 2009.

[23] T. Oeser, R. Wei, T. Baumgarten, S. Billig, C. Föllner, and W. Zimmermann, "High level expression of a hydrophobic poly(ethylene terephthalate)-hydrolyzing carboxylesterase from Thermobifida fusca KW3 in Escherichia coli BL21(DE3)," Journal of Biotechnology, vol. 146, no. 3, pp. 100-104, 2010.

[24] M. A. M. E. Vertommen, V. A. Nierstrasz, M. V. D. Veer, and M. M. C. G. Warmoeskerken, "Enzymatic surface modification of poly(ethylene terephthalate)," Journal of Biotechnology, vol. 120, no. 4, pp. 376-386, 2005.

[25] Y. Tokiwa and T. Suzuki, "Hydrolysis of polyesters by lipases," Nature, vol. 270, no. 5632, pp. 76-78, 1977.

[26] C. Silva, S. Da, N. Silva et al., "Engineered Thermobifida fusca cutinase with increased activity on polyester substrates," Biotechnology Journal, vol. 6, no. 10, pp. 1230-1239, 2011.

[27] E. Marten, R.-J. Müller, and W.-D. Deckwer, "Studies on the enzymatic hydrolysis of polyesters. II. Aliphatic-aromatic copolyesters," Polymer Degradation and Stability, vol. 88, no. 3, pp. 371-381, 2005.

[28] D. Ribitsch, A. O. Yebra, S. Zitzenbacher et al., "Fusion of binding domains to Thermobifida cellulosilytica cutinase to tune sorption characteristics and enhancing PET hydrolysis," Biomacromolecules, vol. 14, no. 6, pp. 1769-1776, 2013.

[29] D. Ribitsch, E. Herrero Acero, A. Przylucka et al., "Enhanced cutinase-catalyzed hydrolysis of polyethylene terephthalate by covalent fusion to hydrophobins," Applied and Environmental Microbiology, vol. 81, no. 11, pp. 3586-3592, 2015.

[30] F.-A. El-Toufaili, G. Feix, and K.-H. Reichert, "Mechanistic investigations of antimony-catalyzed polycondensation in the synthesis of poly(ethylene terephthalate)," Journal of Polymer Science, Part A: Polymer Chemistry, vol. 44, no. 3, pp. 1049-1059, 2006.

[31] K. Hamad, M. Kaseem, and F. Deri, "Recycling of waste from polymer materials: an overview of the recent works," Polymer Degradation and Stability, vol. 98, no. 12, pp. 2801-2812, 2013.

[32] G. Cüçlü, A. Kaşgöz, S. Özbudak, S. Özgümüş, and M. Orbay, "Glycolysis of poly(ethylene terephthalate) wastes in xylene," Journal of Applied Polymer Science, vol. 69, no. 12, pp. 2311-2319, 1998.

[33] N. E. Ikladious, "Recycling of poly(ethylene terephthalate): identification of glycolysis products," Journal of Elastomers \& Plastics, vol. 32, no. 2, pp. 140-151, 2000. 

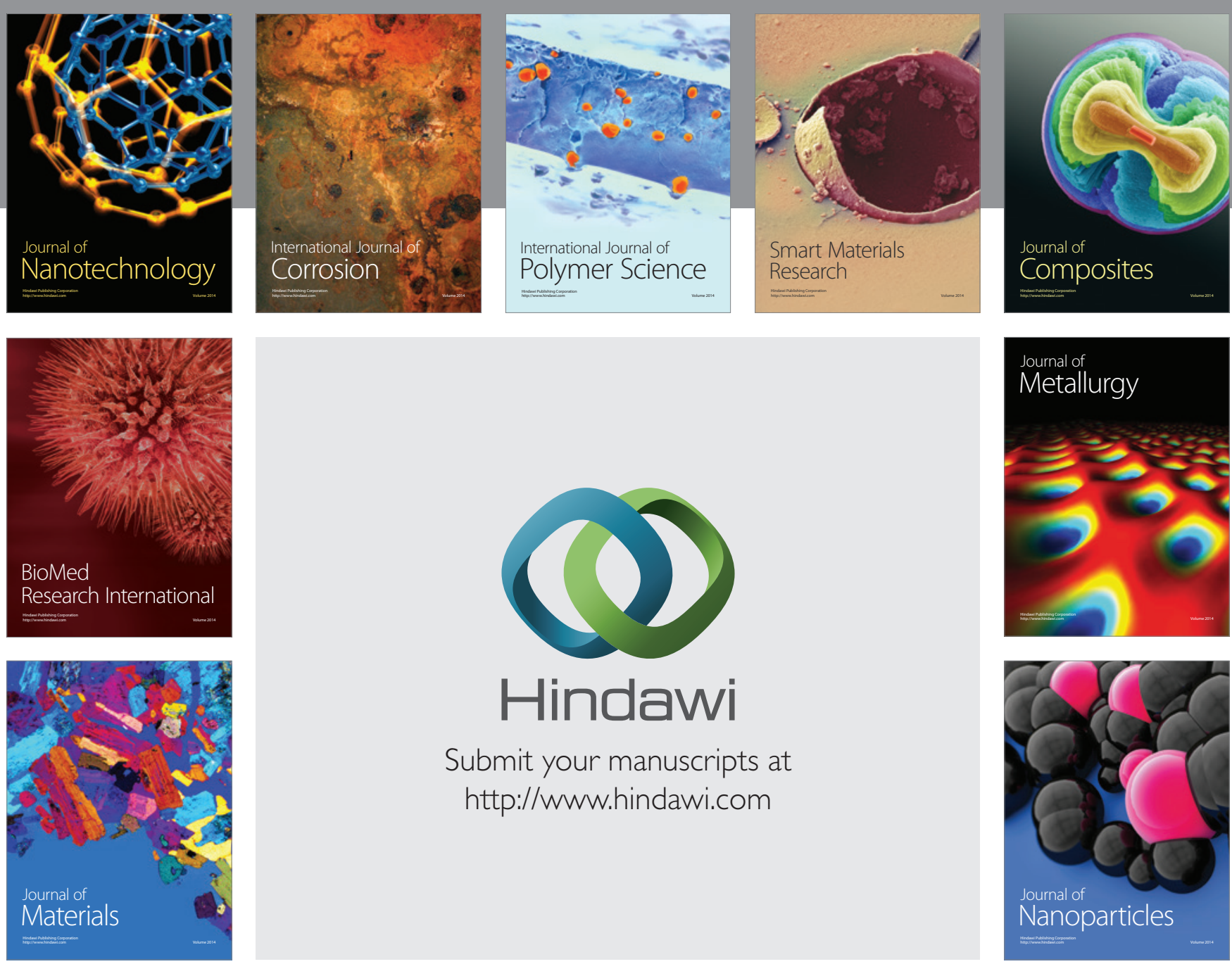

Submit your manuscripts at http://www.hindawi.com
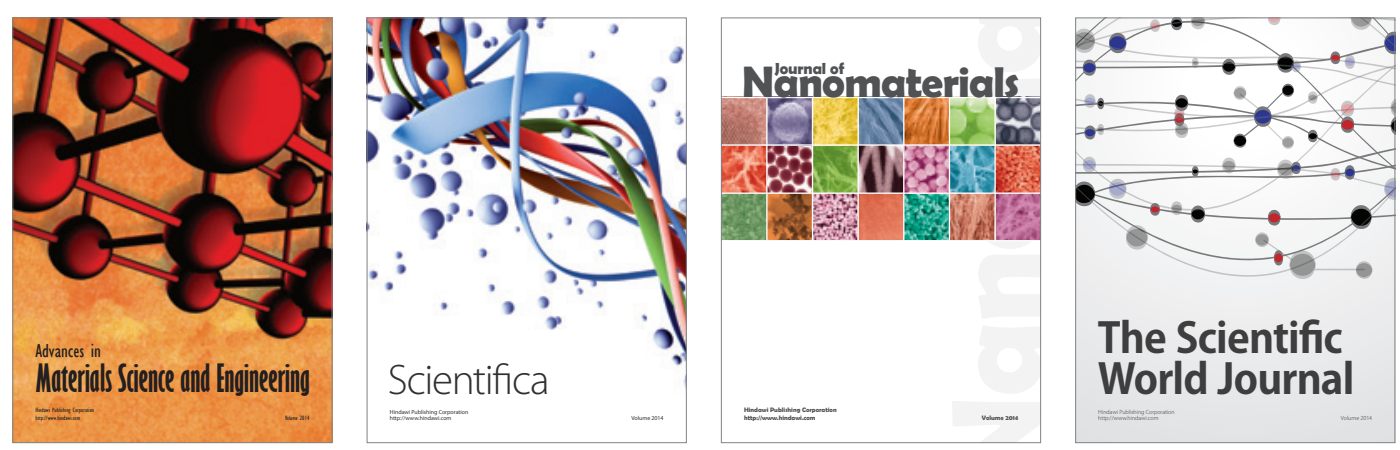

\section{The Scientific World Journal}
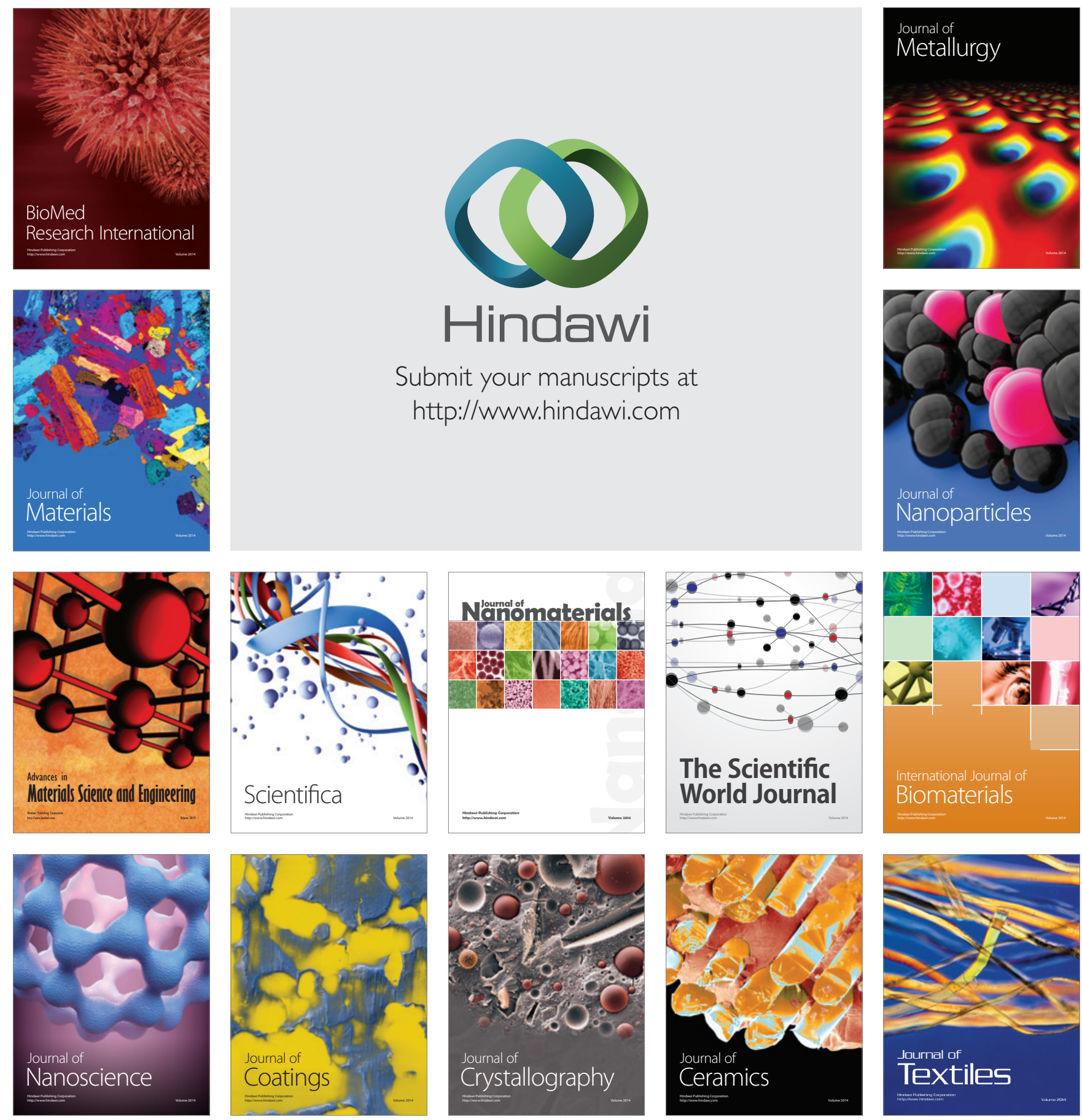